\title{
Translation norms and the translator's agency
}

\author{
He Xianbin
}

\begin{abstract}
Norms and the translator's agency are both sides of every translation activity. The former ensures faithfulness to the source texts, and the latter is the source of creativity. Adherence to and breach of norms both requires the translator's agency.
\end{abstract}

Key words: norms, translator's agency

Translation, as a social activity, is norms-governed. Toury (2001)'s classification of norms shows that every phase of translation, from the selection of texts, to the adoption of an overall cultural stance and the specific strategies, is constrained by norms. John Dryden's metaphor of 'dancing on ropes with fettered legs' refers to the constraints of the source texts and the two linguistic and cultural norms on translation.

On the other hand, translation, as a highly creative task, often requires the practitioners to move beyond some norms. The relationship between norms and agency is hence paradoxical and complex. This paper is an attempt at clarifying their relations.

\section{Change of focus in translator studies}

Concern with the 'how-to' in the interlingual transfer determines the focus of traditional translator studies on the prerequisites for becoming a translator. In ancient Rome, Philo Judaeus (20 B. C ? ---50 A.D ?) and St Augustine (254-430) stressed the significance of 'God's inspiration' to Bible translation and argued that only the pious clergymen were qualified for the job. They prescribed that translators were but dictating tools and there was nothing creative at all in translation. (Tan Zaixi, 1991: 28) In China, one of the first to have commented on translator qualifications is Yan Cong (557-610). In his translation treatise “On Dialectic translation”, Yan listed eight conditions for a translator, half of which were about morality, and another half, educational requirements. These include faithfulness to the Buddhist cause, modesty, discipline, a good command of the Sanskrit and Chinese, knowledge of the Buddhist scriptures and the Chinese classics, etc. (Chen Fukang, 1992: 38) It is impossible for people in his time to possess the 'eight conditions', for 'translators were mostly monolingual then.

These source-oriented researchers are also interested in formulating all sorts of standards for translators to follow. Translators are required to imitate the authors so that the translations do not read like translations. They are the servants of the 'master' authors and are expected to be purely objective, transparent, and invisible.

Scholars in the Manipulation School initiated a target-oriented paradigm in translation studies. They were convinced that, "from the point of view of the target literature, all 
translation implies a degree of manipulation of the source text for a certain purpose (Hermans, 1985: 10)". Translations were one of the primary literary tools that larger social institutions -educational systems, arts councils, publishing firms, and even governments----had at their disposal to 'manipulate' a given society in order to 'construct' the kind of 'culture' desired. Translators are manipulators of the source texts and the target readers, and the manipulating tools of their patronage.

It follows that the paradigm shift in translation studies just means a change from emphasis on the constraints of the source texts and cultures to those of the target cultures. Hardly have translators shaken off the shackles of the source texts and authors when they are again chained by the target cultures.

\section{Possibility and necessity of breaching norms}

Translation is constrained by social and cultural factors. In most cases, it is the publishers who determine the choice of these social factors and the kinds of translations they would like translators to produce. So far as the settlement of specific problems is concerned, the translators obviously have the last say, for they are the only people doing the creative work of translation. Translators are manipulated by the patronage. But as the actual performers of the act of translating, they can at times move beyond the norms.

Breaking norms is closely related to the motivation of translation. As social agents, translators work in a certain context. They have certain goals to reach, personal or collective interests to pursue, and material and symbolic stakes to defend. Some translators are politically motivated and their very purpose is to subvert the dominant norms.

Ideological control of translation is usually strict in a society. But some translators are defiant of or indifferent to the political or ethical norms of the target culture and remain faithful to the source text even if it is hostile or threatening to dominant political or ethical values. And for certain purposes, some would rather challenge the target culture ideological norms and face possible severe punishment.

In the Medieval Period, the Bible was prohibited being translated into vernacular languages. But the attempt of the church authorities finally failed. In the Middle East, similar things happened to the rendition of Koran. In China, during the Cultural Revolution, ideological control of translation went to the extreme. In the five years from May,1965 to November, 1971, not a single translation of foreign literature was published. And in the remaining years of the Cultural Revolution, only a total of 34 translations got printed. But some people secretly translated the Western literature, not to serve the dominant ideology, but just for translation's sake, and their translations came out soon after the end of the Cultural Revolution.

The existence of competing norms in a society involves choices. Translators tend to follow the mainstream norms to be more easily patronized. In some cases, however, particularly in time of cultural transition, several conflicting norms might be equally influential. This enables translators to decide to go with one norm and accept one patronage instead of another. The translator's position is crucial at this moment. One example is that 
during the Sino-Japan War (1937-1945), works in praise of and severely criticizing the Japanese aggression were both translated into Chinese, though in different regions of China.

Breach of poetical norms is very common in literary translation and is diversified by the translator's personal aesthetic preferences. For instance, at the beginning of the $20^{\text {th }}$ century, three kinds of temporal dialects co-existed in the Chinese fiction translation: a). the classical dialect (wenyan); b). the simple classical dialect; and c). the spoken dialect (baihua). Most translators stuck to the use of one form, but some alternated between two. In rendering the same text, some people follow the source culture norms and translate more literally, while others attach greater importance to the readers and produce works with more latitude.

The translator's response to the editors' poetic requirements and critics' comments is also complex. Translators normally obey the obligatory requirements, but may accept or reject the technical suggestions according to their own professional judgment. Some translators may be part of a prevailing trend and thus establish good relationships with critics, while others may insist on their own principles in spite of the critics' opposition.

Breach of norms does not necessarily lead to severe punishment, nor does it mean the invalidity of norms. At times, slight breach of norms is not only tolerated, but also encouraged. "Some literary translators might claim that their intention is precisely to break these norms. And translations of advertisements sometimes appear deliberately to flout the expectancy norms of the target culture. (Chesterman, 1997: 60)"

Norms are "the main factors ensuring the establishment and stability of a social order (Toury, 2001:55)”, but they also restrain innovation. In this sense, they must sometimes be challenged and changed. Otherwise, prejudice will last a long time. Here failure to adhere to norms does not mean anything negative. On the contrary, it is often the source of cultural creativity. Only when the previous norms are broken is it possible for new ones to become dominant, and for cultures to develop.

\section{Translator's agency in different phases of translation}

"The translator's agency is manifested not only in the translator's comprehension, interpretation and artistic re-presentation of the source texts, but also in the selection of source texts, the cultural motivations of translation, the adoption of strategies, and the manipulation in the prefaces of the expected functions of the translations in the target culture. (Cha Mingjian et al, 2003: 22)

The translator's role in text selection varies from time to time. It is usually the publisher who selects source texts and translators. But translators have the right to accept or reject the rendition of certain works.

Regardless of the actual power of translators, text selection has often been an important criterion of translator criticism. A case in point is the different evaluations Yan Fu (1853-1921) and Lin Shu (1852-1924) received. Patriotic motivations and careful selection of the Western social works have often been considered a significant feature of Yan's translation, whereas Lin Shu has been repeatedly criticized for being unselective and having wasted most of his time rendering a large percentage of secondary or third-class literature into Chinese. 
The product of translating is directly shaped by the translator's comprehension of the source texts and the specific strategies he employs. Competence is crucial to the accuracy of translation, but the translator's conscious or unconscious intervention is inevitable, particularly in the forms of ideological and/or poetical deletions, rewritings, and additions. The manipulation exists not only in the translations, but also in the prefaces and postscripts, which are short, conspicuous, and therefore very effective in manipulating the readers to have desired cultural results.

Translators manipulate the source texts in the service of power. They are in turn manipulated by the patronage so that the target reader and society are manipulated. On some occasions, however, translators manipulate their patrons.

"Translation involves trust. The audience, which does not know the original, trusts that the translation is a fair representation of it. (Lefevere, 1990: 15)” The trust from readers and translation commissioners brings some power to translators, the exercise of which is closely connected with the translator's loyalty and reliability. In case translators have access to information unavailable to their clients, or where translators are in short supply, they might make full use of this and manipulate both the source texts and the patrons in order to achieve certain purposes. This helps us to understand why translators who have exclusive or near-exclusive access to information otherwise unavailable to those in power tend to be closely supervised and vetted for political loyalty (Hermans, 1999b: 130).

One example of manipulating the patrons is found in the Treaty of Tientsin (1858), signed between the Qing dynasty feudal court and the British government. Article L of the English version stipulated that

All official communications addressed by the Diplomatic and Consular Agents of Her Majesty the Queen to the Chinese Authorities shall, henceforth, be written in English. They will for the present be accompanied by a Chinese version, but it is understood that, in the event of there being any difference of meaning between the English and the Chinese text, the English government will hold the sense as expressed in the English text to be the correct sense. This provision is to apply to the Treaty now negotiated, the Chinese text of which has been carefully corrected by the English original. (1917, vol. 1: 418)

However, the Chinese text of the same article read somewhat differently, saying that, Henceforth the communication shall be written in English; but until China has selected students for learning the English language and their English has become very fluent, the communication shall be accompanied with a parallel text in Chinese. ...

There is no way of telling how this statement found its way into the Chinese text. For lack of bilingual Chinese, for a long time, the Qing court had relied on the Western missionaries for interpretation in diplomatic communications or signing treaties with the Western countries. Wang kefei and Fan Shouyi (1999) said that the negotiators probably intended to include the statement in the Chinese text in order to force the Emperor to start a language school for training interpreters.

Manipulation in translation is often very subversive, because translation offers a cover for the translator to go against the dominant constraints of his or her time, not in his or her own name, but rather in the name of a writer. This gives the translator two privileges: He 
relies on the authority of the author when he himself is not well known; expressing his own opinions with the discourse of the author, within a certain limit, the translator takes no responsibility for his own statements. Moreover, deviations occurring in translations often meet with greater tolerance. And the way censorship is applied to translations has often been much more lenient. One reason for this difference is that the presumed non-domestic origin of translations makes them look less menacing; another is that there seems to be no way of actually going after the 'absent' author, who should presumably take most of the blame. Translation thus constitutes a convenient way of introducing novelties into a culture, without arousing too much antagonism, especially in cultures reluctant to deviate from sanctioned models and norms. (Toury, 2001: 41).

Translating involves both the source and target norms and this enables translators to make a choice as to which to follow. Translators tend to stay partly within and partly out of these two sets of norms.

\section{Social determinism and the translator's idiosyncrasy}

Government and creativity are two sides of the same translation coin. In contrast to scholars from the philological school, who highly value artistic creation and the translator's freedom in literary translation, scholars in the manipulation school attach greater importance to the cultural constraints on translation. This arouses criticism from some scholars. Antoine Berman, for example, argued that since norms tended to prescribe translations of the naturalizing kind, and translators were supposed to obey norms, a norm-based approach denied all creativity to translation and translators. Anthony Pym commented that a mechanistic application of the norms concept is bound to downgrade the individual translator's agency (in Hermans, 1999b: 154-5).

But Hermans (1999b: 128-132) debates that "constraints are conditioning factors, not absolutes. Individuals can choose to go with or against them. Translators, too, can decide to defer to the powers or foment opposition, be it poetic or political. " He quotes from Bourdieu, saying that two dangers threaten research in the human sciences: naïve teleological or 'finalist' thinking, which sees the end of a known process as illuminating the path towards the goal; and mechanistic determinism, which interprets processes as the inevitable unraveling of a set of initial conditions.

A translator is social and individual, which means he is constrained by social and cultural norms of the time, and at the same time, has his own specific individuality and agency. The translator's agency and the factors that constrain his agency co-exist. On one hand, the translator is sure to be constrained by certain factors in his exercise of agency. On the other, faced with many constraints, the translator still has room to exert his agency. Translation is a combination of universal constraints on translators as a group and much agency of translators as individuals.

"Translation decisions are neither fully predetermined nor totally idiosyncratic (Hermans, 1999b: 74)." Over-emphasis on social constraints and ignoring the translator's agency will result in the fall of the translator's status and responsibility as well as the quality of 
translations. And negligence of the social norms might lead to random translation.

Translation, as a norms-governed creative work, requires the translator to follow his own inclinations, but within an acceptable range of norms. For this, maximum use of the translator's agency is required. Norms ensure faithfulness to the source texts, and the translator's agency is the source of creativity. Adherence to and breach of norms both require the translator's agency.

\section{References}

Cha, Mingjian. 2003. On the subjectivity of the translator. Chinese Translators Journal. Vol. 24, (1).

Chen, Fukang. 1997. History of the Chinese Translation Theories. Shanghai: Shanghai Foreign Languages Education Press.

Chesterman, Andrew. 1997. Memes of Translation: The Spread of Ideas in Literary Translation. Amsterdam/Philadelphia: John Benjamins Publishing Company.

Lefevere, Andre. 1990. Translation: Its Genealogy in the West. in Bassnett, Susan and André Lefevere (eds.). Translation, History and Culture. London and New York: Pinter.

Lefevere, Andre. 1992. Translation, Rewriting and the Manipulation of Literary Fame. London and New York: Routledge.

Hermans, Theo. 1985. The Manipulation of Literature: studies in literary translation. London and Sydney: Croom Helm Ltd.

Hermans, Theo. 1999a. Translation and Normativity. in Schaffner, Christina (ed.). Translation and Norms. Clevedon: Multilingual Matters Ltd.

Hermans, Theo. 1999b. Translation in Systems [M]. Manchester, UK: St Jerome Publishing.

Tan, Zaixi.1991. Brief History of Western Translation. Beijing: The Commercial Press.

Wang, Kefei \& Fan Shouyi. 1999. Translation in China: A Motivating Force. Meta, XLIV, (1).

About the author: He Xianbin, Ph. D, is an associate professor in Guangdong Polytechnic Normal University, China, and academic visitor in Centre for Translation and Inter-cultural Studies, the University of Manchester from 2005 to the end of February 2006.

\section{Postal address:}

He Xianbin

English Department, Guangdong Polytechnic Normal University,

No 293 ZhongShan DaDao, Guangzhou, China, 510665

Tel: 00447871255423 (UK mobile)

Email: binxianhe@126.com, Xianbin.He@manchester.ac.uk

In SKASE Journal of Translation and Interpretation [online]. 2007, vol. 2, no. 1 [cit. 2007-05-03].

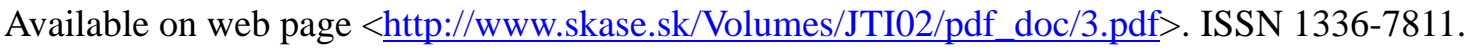

